\title{
Experimental Study of a Dual-Fuel Generator Set Operating on Diesel Fuel Direct Injected and Hydrous Ethanol Fumigation at Different Loads
}

\author{
Giovani D. Telli ${ }^{1}$, Carlos R. Altafini ${ }^{2}$, Carlos A. Costa ${ }^{2}$, Josimar S. Rosa ${ }^{3}$, Luiz A.O. Rocha ${ }^{1,4}$, Giulio Lorenzini ${ }^{5 *}$ \\ ${ }^{1}$ Mechanical Engineering Graduate Program, Federal University do Rio Grande do Sul, R. Sarmento Leite 425, Porto Alegre \\ 90040-001, Brazil \\ ${ }^{2}$ Mechanical Engineering Graduate Program, University of Caxias do Sul, R. Francisco Getúlio Vargas 1130, Caxias do Sul \\ 95070-560, Brazil \\ ${ }^{3}$ Institute of Creative and Technological Sciences, Feevale University, ERS239 2755, Novo Hamburgo 93525-075, Brazil \\ ${ }^{4}$ Mechanical Engineering Graduate Program, University of Vale do Rio dos Sinos, Av. Unisinos 950, São Leopoldo 93022- \\ 000, Brazil \\ ${ }^{5}$ Dipartimento di Ingegneria e Architettura, Università degli Studi di Parma, Parco Area delle Scienze 181/A, Parma 43124, \\ Italy
}

Corresponding Author Email: giulio.lorenzini@unipr.it

https://doi.org/10.18280/ijdne.150602

Received: 4 July 2020

Accepted: 14 October 2020

\section{Keywords:}

dual-fuel combustion, fumigation, ethanol, diesel fuel, compression ignition engine, internal combustion engine, emissions

\begin{abstract}
The sizable global use of fossil energy and the worries about harmful emissions to the environment and human health have led investigations focused on using renewable fuels. Ethanol seems to be a desirable renewable fuel due to availability and significant production. The ethanol fumigation in compression ignition engines has been explored as a possible solution to enhance efficiency and decrease harmful and pollutant gases. This study investigates the effects of a generator set running on directly injected diesel fuel containing 7\% biodiesel in volume and port fuel injected hydrous ethanol in different loads. The experiments were carried out in a diesel engine with specific loads, and the ethanol substitution rate ranged from $9 \%$ to $52 \%$ by energy. Results showed a significant decrease up to $61 \%$ in smoke opacity. An improvement of about $9.7 \%$ at $7.0 \mathrm{~kW}$ in global thermal efficiency was observed. Nevertheless, the other loads' efficiency deteriorated, resulting in a maximum decrease of about $14.6 \%$ at $4.0 \mathrm{~kW}$. The total specific fuel consumption increased when ethanol was used, whereas the exhaust gas temperature decreased. The lowest $\mathrm{NO}_{\mathrm{x}}$ emissions found was $290 \mathrm{ppm}$ at $6.0 \mathrm{~kW}$ and an ethanol energy ratio of $21 \%$, although an increase in $\mathrm{CO}$ emissions was observed.
\end{abstract}

\section{INTRODUCTION}

The world's energy matrix is mostly based on fossil sources; about $83 \%$ of the primary energy in 2013 came from fossil fuels. Besides, in the same year, $31 \%$ of all primary energy in the world came from oil, showing our high dependence and importance of oil for the world [1]. The oil demand tends to increase due to the greater need for energy because of population, economic growth, and improved quality of life. Projections indicate that the energy demand will increase by around $50 \%$ in 2030 [2].

Internal combustion engines (ICE) produce mechanical energy through the combustion process, which mostly uses fossil fuels such as diesel fuel and gasoline. As a result of this process, some polluting gases are formed [3]. Pollution from ICEs is becoming increasingly worrying, affecting air quality, worsening the greenhouse effect, and damaging human health [4]. Compression ignition (CI) engines are frequently used in various sectors, but they are immensely used in the transportation sector due to high efficiency, reliability, and stability [5-7]. In 2014, only the transport sector consumed about $64.5 \%$ of all oil produced, emitting $23 \%$ of all $\mathrm{CO}_{2}$ discharged into the environment [1]. Therefore, the transport sector has the highest final energy consumption and one of the leading global contributors to greenhouse gas emissions [8].

It is essential to investigate CI engines to enhance their efficiency and minimize the environmental impact in this context. Furthermore, it is inevitable to substitute diesel fuel for renewable fuels, considering the exhaustion of fossil fuels and climate change [9]. The most popular ones are ethanol and biodiesel. Ethanol seems to be a desirable renewable fuel to substitute diesel fuel partially. The advantage of replacing diesel fuel for ethanol is utilizing a fuel free from sulfur and heavy metals and is produced by fermentation of carbohydrates using enzymes as catalysts, for example, corn, sugar cane, wheat, potato, and rice [10]. The use of ethanol is interesting because it reduces fossil fuels' consumption and reduces the emissions of pollutant gases that contribute to the greenhouse effect. Also, global ethanol production tends to grow and is superior to the production of other renewable fuels. The largest ethanol producer globally is the USA, with 54\%, followed by Brazil, which produces $30 \%$ of all ethanol produced in the world [11].

The most common methods to replace diesel fuel with ethanol in CI engines are the ethanol and diesel blends method [12-14] and the ethanol fumigation method [15-18]. The blend method is the simplest: mixing ethanol to the conventional diesel fuel and injecting the blend directly into the cylinder 
through the conventional diesel injector. The alcohol-diesel blends help reduce engine emissions without significant impacts on engine performance [19]. The bleeding method's disadvantage is when diesel and ethanol are mixed; both fuels' physicochemical characteristics are affected [20]. Another disadvantage in using diesel-ethanol mixtures is that the proportion of ethanol in the blend is restricted due to diesel fuel and ethanol's poor miscibility.

In the fumigation method, ethanol is usually injected by a port fuel injection (PFI), overcoming the blending method's difficulties. The fumigation method's advantages require minimum engine modifications and allow operation flexibility because they keep the two injection systems separated. According to Boretti [21], this method is one of the best solutions for alcohol use in CI engines and allows higher substitution rates than the blend method.

Imran et al. [22] analyzed the fumigation of alcohol in diesel engines, particularly methanol and ethanol, indicating the effects on emissions and performance parameters. The authors reported that most studies used substitution ratios between $5 \%$ and $40 \%$, and the use of alcohol fumigation methods in CI engines is capable of reducing $\mathrm{CO}_{2}$ emissions, $\mathrm{PM}$, and smoke opacity, although $\mathrm{CO}$ and $\mathrm{HC}$ emissions increase. They also reported an increase in the specific fuel consumption contrasted with diesel fuel results for the loads tested. Lastly, it was highlighted that thermal efficiency deteriorates at low loads and improves at high loads. Chauhan et al. [23] conduct an assessment of the fumigation method on a single-cylinder CI engine working with ethanol and diesel fuel. The engine's rated brake power is $7.5 \mathrm{~kW}$ with a compression ratio of $17.5: 1$ and diesel start of injection (SOI) of $26^{\circ}$ bTDC. The substitution rates varied from $3 \%$ to $48 \%$ by energy, and engine load ranged from 0 to $100 \%$. They reported that ethanol fumigation decreases the exhaust gas temperature and decreases $\mathrm{NO}_{\mathrm{x}}, \mathrm{CO}, \mathrm{CO}_{2}$ concentrations. However, hydrocarbon emissions increased in all loads.

Han et al. [24] studied the duel-fuel operation in a heavyduty diesel engine, six cylinders with a compression ratio of 15.85:1. Ethanol was injected into the intake port while diesel was directly injected into the cylinder. The results indicated that up to $80 \%$ of ethanol mass ratios could be achieved at medium and low loads. The thermal efficiency decreases at a low load when ethanol is injected. However, at medium to high loads, thermal efficiency first increases to $50.7 \%$ and $49.7 \%$, respectively, then decreases due to sub-optimal combustion phasing at high ethanol mass ratios. Concerning the emissions, ethanol can reduce soot emissions, with no consistent effects on $\mathrm{NO}_{\mathrm{X}}$ emissions. As the ethanol mass ratio increases, the $\mathrm{HC}$ and $\mathrm{CO}$ emissions increase due to incomplete combustion in dual-fuel operation.

Ferreira et al. [25] evaluated the diesel engine's performance and emissions characteristics running with blends of diesel and biodiesel indirect injected and ethanol port fuel injected. The authors carried out the experiments in a diesel engine with a compression ratio of 20:1 at $1800 \mathrm{rpm}$ and $1.58 \mathrm{~kW}$ (about $20 \%$ of load). The volumetric ratios of ethanol varied from $0 \%$ to $15.2 \%$, and one sample was tested with $15.2 \%$ of ethanol and $0.4 \%$ of di-tert-butyl peroxide. In general, engine efficiency decreased, and energy consumption was higher when ethanol was used. The emissions characteristics revealed a decline in $\mathrm{NO}_{\mathrm{X}}$ and smoke opacity, while $\mathrm{CO}$ and $\mathrm{HC}$ emissions increased. The use of di-tert-butyl peroxide as an additive resulted in a slight improvement in efficiency and decreased the $\mathrm{CO}$ and hydrocarbon emissions. Rosa et al. [26] tested a similar engine (with the diesel SOI of $17^{\circ} \mathrm{bTDC}$ ) running on ethanol and wet ethanol (a maximum of $30 \%$ of water concentration) but with a fixed load of $6 \mathrm{~kW}$. The ethanol mass fractions ranged from $10.6 \%$ to $60.6 \%$. The fuel conversion efficiency increased by up to $10 \%$ when ethanol and wet ethanol were used. The emissions characteristics results found a decrease in $\mathrm{NO}_{\mathrm{x}}$ and smoke opacity. However, carbon monoxide emissions increased with ethanol addition. The emissions result showed the same trends as those reported by Ferreira et al. [25].

Tsang et al. [27] conduct fumigation experiments on a 4cylinder diesel engine with a compression ratio of 19:1 and diesel injection timing of $8^{\circ} \mathrm{bTDC}$. The tests were carried out at a constant speed of $1800 \mathrm{rpm}$ with different loads and four substitution ratios, ranging from $5 \%$ to $20 \%$. The results indicated a drop in thermal efficiency at low and mid loads, and no substantial change was noted for high loads. The use of ethanol leads to a decline in $\mathrm{NO}_{\mathrm{X}}, \mathrm{PM}$, and smoke opacity for all conditions analyzed. However, a significant increment in the fuel consumption and emissions of $\mathrm{HC}, \mathrm{CO}$, and $\mathrm{NO}_{2}$ was observed. The authors also perform tests with an oxidation catalyst, and it was possible to diminish the high $\mathrm{HC}$ and $\mathrm{CO}$ emissions generated by the fumigation method. The emissions results agree with those obtained by López et al. [28], which carried out the experiments in a turbocharged, four-cylinder diesel engine with a compression ratio of 18.4:1 at $2410 \mathrm{rpm}$. Comparable results were also found by Zhang et al. [29], which also studied the ethanol and methanol fumigation method with a maximum substitution ratio of $20 \%$ in a 4 cylinder, direct injection CI engine with a compression ratio of 19:1 and a speed of $1800 \mathrm{rpm}$.

De Oliveira et al. [30] investigated a four-cylinder CI engine with a compression ratio of $17: 1$ working on direct-injected diesel fuel having 7\% biodiesel (B7) and hydrous ethanol port fuel injection (PFI). The diesel injection timing was fixed at $23^{\circ} \mathrm{bTDC}$, and the load varied from 0 to $37.5 \mathrm{~kW}$ during the tests. The authors varied the substitution ratio of ethanol between 5 to $30 \%$. The results showed that fuel conversion efficiency decreased at low loads, achieving the highest reduction of about $6.6 \%$. However, for high loads, the fuel conversion efficiency was enhanced by up to $13 \%$ compared to conventional diesel combustion. In general, the emissions of $\mathrm{CO}_{2}$ and $\mathrm{NO}$ were lower than conventional diesel combustion for all conditions analyzed. The most significant $\mathrm{CO}_{2}$ and $\mathrm{NO}$ emissions reductions were about $12 \%$ and $53 \%$, with ethanol injection of $30 \%$. The results also indicated that ethanol's use to replace diesel fuel partially increased the emissions of $\mathrm{CO}, \mathrm{HC}$, and $\mathrm{NO}_{\mathrm{X}}$ for all loads tested.

Jamuwa et al. [31] investigated the ethanol fumigation method on a $3.7 \mathrm{~kW}$, single-cylinder CI engine with a compression ratio of $16.5: 1$ and SOI $23^{\circ}$ bTDC. The experiments were conducted at a constant speed of $1500 \mathrm{rpm}$ using nine specific loads and five ethanol mass flow rates. At low loads, the results showed that the thermal efficiency decreased around $11.2 \%$ and at high loads increased by about $6 \%$ in respect of diesel fuel baseline. In terms of emissions, the authors reported a reduction in the smoke index, $\mathrm{NO}$ and $\mathrm{CO}_{2}$ emissions, whereas $\mathrm{HC}$ and $\mathrm{CO}$ emissions increased compared to the diesel fuel baseline. In another work from Jamuwa et al. [32], they also found the same trend results.

According to the literature above, the significance of studying diesel engines running on diesel-ethanol by the fumigation method is straightforward. There is a great interest in improving these engines' efficiency and reducing emissions 
of polluting gases, making their use more sustainable and ecofriendlier. In this context, this work experimentally evaluates the effects on the performance and emissions of a generator set equipped with a diesel engine running on diesel fuel (with $7 \%$ of biodiesel - B7 in vol.) and hydrous ethanol (with $4.5 \%$ of the water in vol.). This research aimed to expand the knowledge of ethanol's use in compression ignition engines on dual-fuel mode. The combination of parameters used in this research (number of cylinders, fuel composition, diesel direct injection angle, compression ratio, speed, a variation of load, and substitution ratio) does not match the parameters studied in previous research. This information demonstrates how this research contributes to expanding knowledge on the use of ethanol in diesel engines.

Another purpose of this paper is to study the use of a low carbon renewable fuel, such as hydrous ethanol, substituting partially diesel fuel in the engine. The benefits of this use are the reduction of pollutant emissions and the reduction of fossil fuel use. The engine used in the tests has many applications, such as agricultural machines and power generation. These applications can then be more sustainable and reduce their environmental impact using ethanol in dual-fuel mode. Besides, it is an option for small farmers who can produce their ethanol fuel from different crops, allowing their farm use. Finally, since this technology of dual-fuel mode is not yet commercialized, there are still many points to explore about diesel engines' capability fuelled partially with ethanol, and this paper helps to improve this understanding.

\section{MATERIALS AND METHODS}

\subsection{Experimental setup}

A single-cylinder stationary diesel engine was used in the experiments. Table 1 displayed the test engine specification. The electric generator used has $8.0 \mathrm{~kW}$ of power, and the electric loads for the experiments were achieved using electric resistances. The engine speed was kept constant at $1800 \mathrm{rpm}$ in all conditions tested.

In the experiments were employed hydrous ethanol (HET) with $95.5 \%$ purity and diesel fuel (B7) with $7 \%$ biodiesel. The physicochemical properties of the fuels used in the research were measured in the paper [17] and are listed in Table 2. Figure 1 illustrates a schematic of the experimental setup with its fundamental parts.

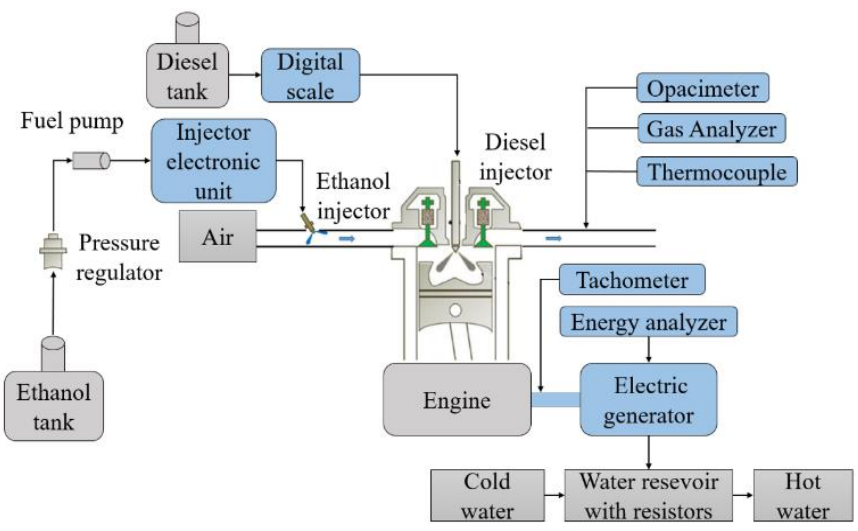

Figure 1. Experimental scheme

The engine standard injection fuel system introduces diesel fuel (B7). Nonetheless, a port fuel injector system was mounted at the engine air inlet manifold when the engine is submitted to the ethanol fumigation method. As shown in Figure 1, the ethanol PFI system has four components: an ethanol injector with a flow of $18-21 \mathrm{~mL} / \mathrm{min}$, a pressureregulated valve fixed at 4.5 bar, a fuel pump, and an electronic injection unit to manage the ethanol mass flow rate.

Table 1. Test engine specification

\begin{tabular}{cc}
\hline Engine characteristics & Specification \\
\hline Type & Single cylinder, air cooled \\
Bore $(\mathrm{mm})$ x Stroke $(\mathrm{mm})$ & $90 \times 105$ \\
Displacement $(\mathrm{cc})$ & 668 \\
Compression ratio & $20: 1$ \\
Maximum power $(\mathrm{kW} / \mathrm{rpm})$ & $8.8 / 2400$ \\
Injection type & Direct injection \\
Injection pressure (bar) & 180 \\
Injection timing & $21^{\circ}$ BTDC \\
\hline
\end{tabular}

Table 2. Diesel fuel (B7) and hydrous ethanol properties [17]

\begin{tabular}{ccc}
\hline Fuel properties & B7 & HET \\
\hline Density at $20^{\circ} \mathrm{C}\left(\mathrm{g} / \mathrm{cm}^{3}\right)$ & 0.843 & 0.806 \\
Viscosity $(\mathrm{cP})$ at $20^{\circ} \mathrm{C}$ & 3.52 & 0.5 \\
Lower heating value $(\mathrm{J} / \mathrm{g})$ & 42,651 & 23,922 \\
Carbon $(\%)$ & 86.08 & 48.63 \\
Hydrogen $(\%)$ & 12.44 & 13.14 \\
Nitrogen $(\%)$ & 0.04 & 0.03 \\
Oxygen + Halogens + Ashes $(\%)$ & 1.4 & 38.2 \\
Sulfur $(\%)$ & 0.04 & 0 \\
\hline
\end{tabular}

The diesel fuel (B7) consumption was assessed with a digital scale with $0.01 \mathrm{~g}$ of resolution and an uncertainty of 1 g. The energy analyzer Embrasul RE6000 was used to supervise the generator's electrical parameters, such as current, voltage, power, and frequency. The equipment has a measuring range from 50 to $500 \mathrm{~V}$ for $\mathrm{AC}$ voltage with a 0.01 $\mathrm{V}$ of resolution and from 0.2 to $1000 \mathrm{~A}$ for $\mathrm{AC}$ with $0.01 \mathrm{~A}$ of the resolution and a $0.2 \%$ accuracy. A K-type thermocouple was fixed at the engine exhaust manifold to determine the discharge gas temperature. The thermocouple has an accuracy of $\pm 0.75 \%$, a resolution of $0.1{ }^{\circ} \mathrm{C}$, and a measuring range of 50 and $1300^{\circ} \mathrm{C}$.

The smoke opacity was measured using an opacimeter NA9000 model, Napro brand. The opacimeter has the following specifications: accuracy of $\pm 2 \%$, resolution of 0.1 , measurement range from 0 to $99 \%$. The emissions were measured only at $6.0 \mathrm{~kW}$, collecting the combustion gases samples at the engine exhaust manifold. The gas analyzer used was Eurothron brand, GreenLine 8000, with 1 ppm of resolution and $4 \%$ uncertainty in the measured range. The emissions analyzer measures the concentrations of $\mathrm{CO}, \mathrm{SO}_{2}$, and $\mathrm{NO}_{2}$ in ppm, the percentages of $\mathrm{O}_{2}$ and $\mathrm{CO}_{2}$, excess air.

\subsection{Uncertainty analysis}

The uncertainty analysis was based on Eq. (1) based on Kline e Mcclintock [33]. $\mathrm{R}$ is in the function of more than one independent variable, $R=\left(x_{1}, x_{2}, x_{3}, \ldots, x_{n 1}\right)$, and $\mathrm{I}_{\mathrm{n}}$ is the instrument uncertainty.

$$
\mathrm{I}_{\mathrm{R}}=\sqrt{\left(\frac{\partial \mathrm{R}}{\partial \mathrm{x}_{1}} \mathrm{I}_{1}\right)^{2}+\left(\frac{\partial \mathrm{R}}{\partial \mathrm{x}_{2}} \mathrm{I}_{2}\right)^{2}+\left(\frac{\partial \mathrm{R}}{\partial \mathbf{x}_{\mathrm{n}}} \mathbf{I}_{\mathrm{n}}\right)^{2}}
$$


The global thermal efficiency and specific fuel consumption uncertainty analysis were calculated according to Eq. (1). The analysis resulted in uncertainties of $2.0 \%$ in specific fuel consumption and $0.7 \%$ in global thermal efficiency. The results presented directly considered the uncertainties informed by the manufacturers of each instrument, as mentioned above.

\subsection{Engine operation conditions and experimental test procedure}

The experiment was performed for four different loads and four ethanol mass flow rate. The loads used were 4.0, 5.0, 6.0 $7.0 \mathrm{~kW}$, which were achieved with electrical resistances immersed in a plenum with water. The ethanol energy ratio varied from $0 \%$ (conventional diesel combustion) to $52 \%$. These values were obtained by varying the amount of ethanol injected, which was possible using an electronic injection unit, which controlled the injector nozzle opening time. The times selected for this experiment were 2.00, 3.40, 4.78, and $6.16 \mathrm{~ms}$. The maximum substitution rate achieved in this work was $52 \%$. For values above this, the knock effect was noted. Other studies also reported similar maximum ethanol energy ratios $[17,22]$.

The test procedures were as follows: initially, the engine was started running on diesel fuel only at $7.0 \mathrm{~kW}$ to warm up until the lubricant oil temperature was constant. After that period, the mono fuel tests began from $4.0 \mathrm{~kW}$ to $7.0 \mathrm{~kW}$. The duel fuel experiments were then carried out, introducing hydrous ethanol at the inlet manifold, with four different ethanol flow rates for each load tested. The ethanol injection increases the generator speed, exceeding $1800 \mathrm{rpm}$, so the injection of diesel fuel must be reduced to return and maintain the generator speed constant at $1800 \mathrm{rpm}$. This process was followed for all injector opening times tested.

The composition and temperature of the exhaust gases, engine power and speed, relative air humidity, and atmospheric pressure were measured and recorded during the experiments. The experiment procedures follow NBR ISO 3046/1 standard to correct the fuel consumption and power data to the standard reference.

The ethanol energy ratio can be calculated according to Eq. (2) and means the amount of diesel energy substituted by ethanol energy [34].

$$
\% E R=\frac{\dot{m}_{H E T} L H V_{H E T}}{\dot{m}_{H E T} L H V_{H E T}+\dot{m}_{B 7} L H V_{B 7}} \cdot 100
$$

where, the ethanol energy ratio is represented by $\% E R, \dot{m}$ is the ethanol or diesel (B7) fuel mass flow rate in $\mathrm{g} / \mathrm{s}$, and the lower heating value of the fuels is represented as $L H V$ in $\mathrm{J} / \mathrm{g}$.

Eq. (3) describes the total specific fuel consumption $\left(S F C_{T}\right)$ for dual fuel mode, expressed in $\mathrm{g} / \mathrm{kWh}$.

$$
S F C_{T}=\frac{\dot{m}_{H E T}+\dot{m}_{B 7}}{P} \cdot 3600
$$

where, electrical power measured during the experiments by the energy analyzer is represented by $P$ in $\mathrm{kW}$.

Global thermal efficiency $(\eta)$ was defined as:

$$
\eta_{B 7-H E T}=\frac{1000 \cdot P}{\left(\dot{m}_{B 7} L H V_{B 7}+\dot{m}_{H E T} L H V_{H E T}\right)}
$$

\section{RESULTS AND DISCUSSION}

\subsection{Total specific fuel consumption}

Figure 2 presents the engine's total specific fuel consumption $\left(\mathrm{SFC}_{\mathrm{T}}\right)$ for different loads and substitution rates. This figure shows a clear trend of decreasing total specific fuel consumption when load increase and increasing when \%ER increases.

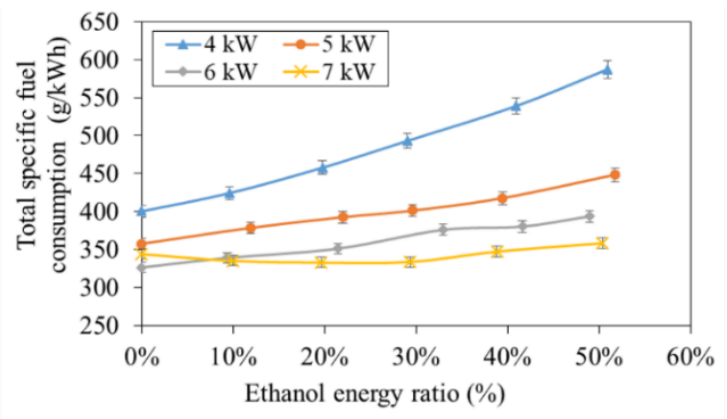

Figure 2. Total specific fuel consumption

The most significant increase in $\mathrm{SFC}_{\mathrm{T}}$ was observed at 4.0 $\mathrm{kW}$, where the engine running on conventional diesel combustion was about $400 \mathrm{~g} / \mathrm{kWh}$ and increased up to 587.5 $\mathrm{g} / \mathrm{kWh}$ for $51 \%$ of substitution rate. This increase is the highest value found in the experiments and represents an increase of about $60 \%$ of the total specific fuel consumption compared to diesel fuel only. However, no significant increase in $\mathrm{SFC}_{\mathrm{T}}$ at $7.0 \mathrm{~kW}$ was found with ethanol. The increase was about $4 \%$ when comparing $0 \%$ and $50 \%$ of $\% \mathrm{ER}$.

Figure 2 also shows that the minimum value of total specific fuel consumption was about $327.0 \mathrm{~g} / \mathrm{kWh}$ for diesel fuel operation only at $6.0 \mathrm{~kW}$ and increased when hydrous ethanol was injected, reaching the value of $394.0 \mathrm{~g} / \mathrm{kWh}$ for $50 \%$ of substitution rate. This finding was expected and suggests that the cause is the lower heating value of hydrous ethanol than diesel fuel. In Table 2, it is possible to notice a significant difference of $44 \%$ in the lower heating value of B7 relative to HET. Consequently, a considerable amount of ethanol is required to generate the same amount of energy when running on B7 only. These results are in accord with recent studies from the paper [23].

\subsection{Global thermal efficiency}

The results of global thermal efficiency (GTE) obtained from Eq. (4) are presented in Figure 3. What stands out in this figure is the general pattern of efficiency growth with increasing load, except at $7.0 \mathrm{~kW}$ and small values of ethanol energy ratio, where GTE at $6.0 \mathrm{~kW}$ is the highest. However, the opposite trend was found when the ethanol energy ratio increases, resulting in lower global thermal efficiencies, except at $7.0 \mathrm{~kW}$ load, which has increased.

It is apparent from Figure 3 that the highest deterioration in global thermal efficiency occurred for the lowest load-tested, $4.0 \mathrm{~kW}$. The GTE for mono fuel operation at $4.0 \mathrm{~kW}$ was $21.2 \%$. When the ethanol energy ratio increases to $51 \%$, global thermal efficiency decreases to $18.1 \%$, representing a reduction of $14.6 \%$ and the lowest GTE value found in the experiments. This reduction in global thermal efficiency using hydrous ethanol has been even more reduced as the load has increased. At $5.0 \mathrm{~kW}$, GTE decreases about $3.4 \%$ in respect of 
$0 \%$ and $52 \%$ of ethanol energy ratio. However, no significant differences in global thermal efficiency were found between diesel fuel operation and $49 \%$ of ethanol energy ratio at 6.0 $\mathrm{kW}$, only a small difference of $1.5 \%$.

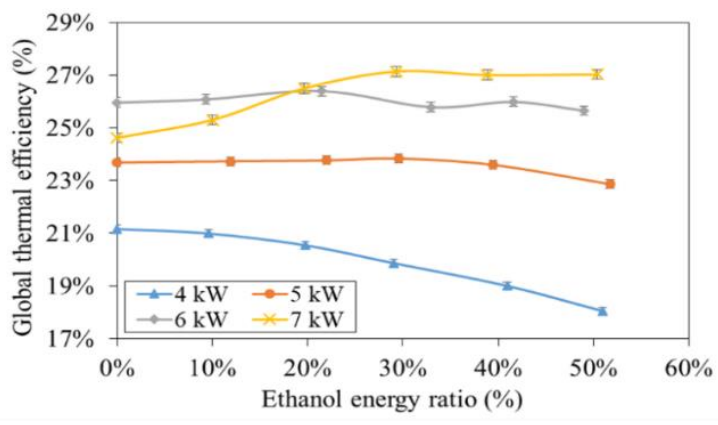

Figure 3. Global thermal efficiency

Interestingly, the global thermal efficiency increased with hydrous ethanol fumigation at $7.0 \mathrm{~kW}$. GTE's improvement was about $9.7 \%$, starting from $24.6 \%$ for diesel fuel operation, and reached the maximum efficiency of about $27.0 \%$ running on $50 \%$ of hydrous ethanol. Overall, these results indicate that there is a reduction in global efficiency for low loads, while for high loads, there is an improvement.

The reduction in global thermal efficiency at low loads when hydrous ethanol was used may be explained by the fact that ethanol has a higher latent heat of vaporization than diesel fuel, about $0.92 \mathrm{MJ} / \mathrm{kg}$ in comparison to $0.23-0.60 \mathrm{MJ} / \mathrm{kg}$ of diesel fuel. In this regard, the introduction of hydrous ethanol at the inlet manifold provides the charge's cooling, which may decrease the in-cylinder temperature. Since the in-cylinder temperature is lower than high load at low load, the ethanol cooling makes it more difficult to ignite all the charge and maintain the combustion, resulting in a poor fuel conversion and, as a consequence, a lower global thermal efficiency. However, at higher loads, for example, $7.0 \mathrm{~kW}$, the in-cylinder temperature is superior, facilitating the ignition of the cooled charge and making it easier to maintain HET's combustion. Besides, ethanol has a lower cetane number (5-8) than diesel fuel (40-55). Consequently, it increases ignition delay in comparison to diesel. Therefore, the time to release the energy when combustion starts is shorter, reducing heat losses between the gases and the cylinder wall, which increases the thermal efficiency [27].

\subsection{Exhaust gas temperature}

Figure 4 provides the exhaust gas temperature (EGT) experimental results for specific loads and ethanol energy ratios tested. From the figure, it is apparent that the EGT increases as the load increases, and when the substitution rate increases, the exhaust gas temperature shows a tendency to decline, mainly at 6.0 and $7.0 \mathrm{~kW}$. The EGT of $440.3^{\circ} \mathrm{C}$ was the highest found, which decreased when hydrous ethanol was injected, achieving a value of $380.3^{\circ} \mathrm{C}$ when running on $50 \%$ of hydrous ethanol. It was the most significant EGT reduction, representing a decrease of about $13.6 \%$ from conventional diesel combustion. However, for lower loads, 4.0 and $5.0 \mathrm{~kW}$, no difference greater than $1.5 \%$ was observed when hydrous ethanol was used. These results support the global thermal efficiency results and explanations mentioned before.

These results may be explained by the fact that ethanol fumigation decreases the charge's temperature entering the cylinder, which also reduces the in-cylinder temperature and, consequently, the exhaust gas temperature. The cetane number of ethanol decreases, so the ignition delay is more extended, reducing the EGT. These results are in agreement with those obtained by the papers $[6,17,25]$.

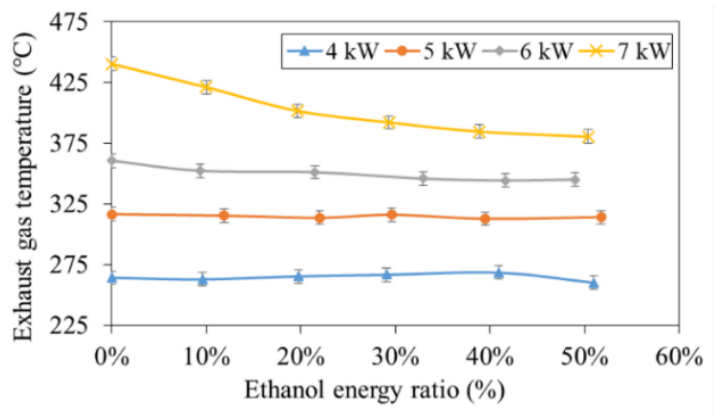

Figure 4. Exhaust gas temperature

\subsection{Smoke opacity}

Figure 5 illustrates the smoke opacity results for various ethanol energy ratios and loads. The most interesting aspect of this graph is that hydrous ethanol decreases the smoke opacity considerably. It is visible from Figure 5 that, for each load tested, the highest smoke opacity was found when the engine worked only on diesel fuel. The highest smoke opacity found was $66 \%$ at $7.0 \mathrm{~kW}$ for $0 \%$ of ethanol energy ratio. When HET was fumigated, the smoke opacity reduces, reaching a value of $26 \%$, meaning a significant reduction of $61 \%$, with the engine running on $50 \%$ of hydrous ethanol. The minimum smoke opacity value found was $21 \%$ obtained at $6.0 \mathrm{~kW}$ and $49 \%$ of the substitution rate.

Following the present results, previous studies from Jamuwa et al. [31, 32] and Chauhan et al. [23] have demonstrated that ethanol fumigation decreases smoke opacity. These results are likely to be related to less carbon in hydrous ethanol compositions than diesel fuel (B7), $48.6 \%$, and $86.1 \%$, respectively, as described in Table 2 . In this regard, on dual fuel mode, a lower quantity of diesel fuel is used. As a consequence, less carbon is burned, reducing the smoke opacity.

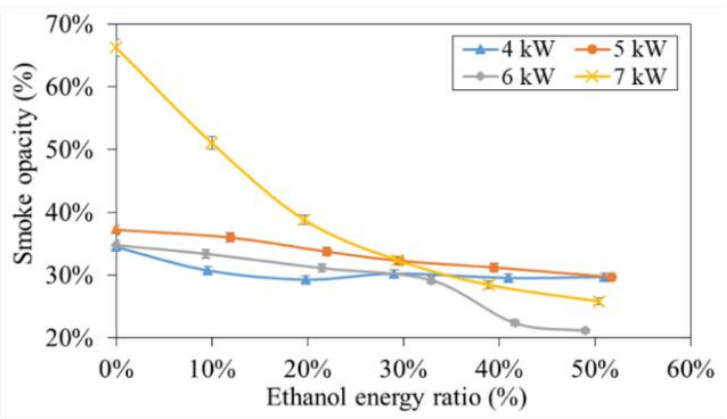

Figure 5. Smoke opacity

\subsection{Carbon monoxide emissions}

Carbon monoxide emissions were measured using the gas analyzer, which was fixed at an engine exhaust manifold. The production of $\mathrm{CO}$ is related to the incomplete fuel burning and the combustion temperature. The $\mathrm{CO}$ emissions results for various ethanol energy ratios at $6.0 \mathrm{~kW}$ are shown in Figure 6. 
It is apparent from Figure 6 that when the engine starts to run on hydrous ethanol and diesel fuel, carbon monoxide increase compared to mono fuel operation. The minimum value of CO emission found was $497 \mathrm{ppm}$ for diesel fuel only, and the maximum value was $2209 \mathrm{ppm}$ for $49 \%$ of the substitution rate, leading to a substantial increase in $\mathrm{CO}$ emissions. This result is in line with previous studies [22, 27, 29], which found similar trends in $\mathrm{CO}$ emission results. A possible explanation for this significant increase in carbon monoxide emissions with the use of HET is the decrease of incylinder temperature caused by the ethanol cooling effect, which makes harder the complete oxidation of $\mathrm{CO}$ to $\mathrm{CO}_{2}$. Besides, the oxygen concentration in hydrous ethanol composition is higher than diesel fuel, so more oxygen is available for combustion when HET is used, which favors carbon monoxide formation.

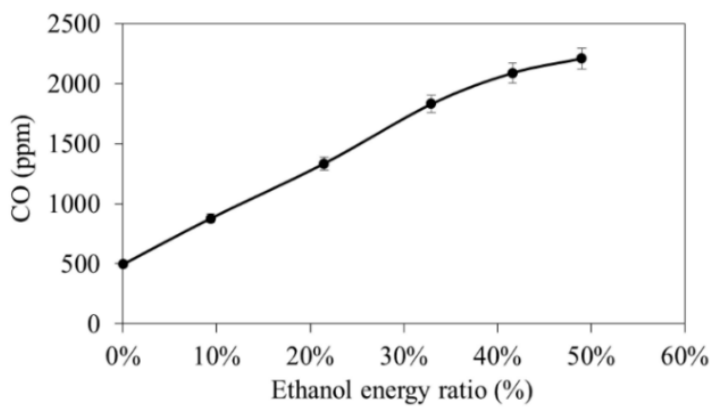

Figure 6. $\mathrm{CO}$ emissions at $6.0 \mathrm{~kW}$

\subsection{NOx emissions}

Figure 7 presents the experimental results of $\mathrm{NO}_{\mathrm{X}}$ emissions for different ethanol substitution rates at $6.0 \mathrm{~kW}$. As can be seen from the figure, the highest $\mathrm{NO}_{\mathrm{X}}$ emission was $365.3 \mathrm{ppm}$ when the engine operates on conventional diesel combustion. The fumigation method's use of hydrous ethanol positively affected $\mathrm{NO}_{\mathrm{X}}$ emissions, reducing about $20.6 \%$ was observed from $0 \%$ to $21 \%$ of ethanol energy fraction. However, no significant differences greater than $2 \%$ were found between ethanol energy fractions higher than $21 \%$ after this point. These results agree with the findings of other studies [23, 27 , 29], in which a decrease in $\mathrm{NO}_{\mathrm{X}}$ emission with ethanol fumigation was reported. However, this outcome is contrary to De Oliveira et al. [30], who found an increase in $\mathrm{NO}_{\mathrm{X}}$.

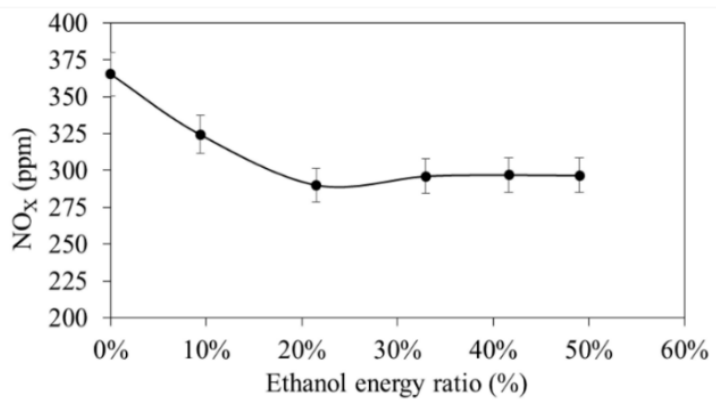

Figure 7. $\mathrm{NO}_{\mathrm{x}}$ emissions at $6.0 \mathrm{~kW}$

The decrease in $\mathrm{NO}_{\mathrm{x}}$ emissions with the hydrous ethanol injection may be explained by the higher ethanol latent heat of vaporization, which may reduce the in-cylinder temperature, and as a consequence, less $\mathrm{NO}_{\mathrm{X}}$ is formed by the Zeldovich mechanism. However, the $\mathrm{NO}_{\mathrm{X}}$ emissions were constant, with $\%$ ER higher than $21 \%$. A possible explanation for this might be that hydrous ethanol has more oxygen in its composition than diesel fuel. In this context, when ethanol energy ratio increases, more ethanol was used, meaning a higher amount of oxygen available for combustion, favoring the $\mathrm{NO}_{\mathrm{X}}$ formation. Nevertheless, the in-cylinder temperature was reduced due to the ethanol cooling effect. Therefore, these two factors may have been counterbalanced and held the formation of $\mathrm{NO}_{\mathrm{X}}$ constant between $21 \%$ and $49 \%$ of ethanol energy fraction.

\section{CONCLUSION}

This research study the performance and emissions characteristics of a generator set working on direct injection of diesel fuel (B7) and port fuel injection of hydrous ethanol at various loads and substitution rates. This work helps reduce emissions of pollutant gases and diminish our dependency on fossil fuel, especially diesel fuel. It also improves the understanding of the utilization of low-carbon fuels, such as ethanol, in compression ignition engines running on dual fuel mode.

This study conducts the experiments in a CI engine connected to a generator at a speed of $1800 \mathrm{rpm}$ and four distinct loads. The injection of hydrous ethanol was performed in four different mass flow rates, reaching 9.0 to $52.0 \%$ of $\%$ ER. The global thermal efficiency and total specific fuel consumption were analyzed to evaluate the generator set's performance, and smoke opacity, $\mathrm{CO}$, and $\mathrm{NO}_{\mathrm{X}}$ were studied to evaluate the emissions characteristic. The key results of this work are:

(a) The total specific fuel consumption increases when the ethanol energy ratio increases and decreases as the load increases. The highest increase was $46.7 \%$ at $4.0 \mathrm{~kW}$ and $51 \%$ of $\% \mathrm{ER}$ compared to conventional diesel combustion. This considerable increase in $\mathrm{SFC}_{\mathrm{T}}$ is explained by the lower heating value of ethanol than diesel fuel, requiring more fuel to maintain the same load.

(b) Generally, the global thermal efficiency decreases at low loads $(4.0$ and $5.0 \mathrm{~kW})$ and increases at high loads $(7.0$ $\mathrm{kW}$ ) when the hydrous ethanol fumigation method is used. However, at $6.0 \mathrm{~kW}$, no difference greater than $1.5 \%$ was observed. The lowest GTE found was $18.1 \%$ at $4.0 \mathrm{~kW}$ and $51 \%$ of $\% E R$, meaning a $14.6 \%$ reduction compared to baseline operation. The highest GTE was $27.0 \%$ at 7.0 $\mathrm{kW}$, an improvement of $9.7 \%$ compared to the B7 baseline operation. The deterioration in global thermal efficiency is because of the ethanol cooling effect, which reduces the temperature inside the cylinder. As a result, B7 had difficulties to ignite and maintain adequate combustion. At a high load $(7.0 \mathrm{~kW})$, the temperature inside the cylinder is higher, making it easier to start and maintain HET's combustion.

(c) The exhaust gas temperature decreases as the ethanol energy ratio increases. The decrease in EGT is more significant at higher loads than lower loads. At 4.0 and 5.0 $\mathrm{kW}$, a slight decrease was observed. Otherwise, at $7.0 \mathrm{~kW}$, the reductions were about 4.4 to $13.6 \%$. The cause of this decline in the EGT is the drop in-cylinder temperature occasioned by the HET injection, which also affects the exhaust gas temperature.

(d) The use of hydrous ethanol in dual fuel mode operation had a beneficial impact on smoke opacity. The results 
showed a considerable drop in the smoke opacity for all conditions tested. The highest decrease was about $61 \%$ at $7.0 \mathrm{~kW}$ for $50 \%$ of the substitution rate. The leading cause is that hydrous ethanol has less carbon in its composition in comparison to B7. Consequently, there is less propensity to produce particulate matter.

(e) The $\mathrm{CO}$ emissions at $6.0 \mathrm{~kW}$ increases as the ethanol energy ratio increases. A substantial increase of $344 \%$ was observed in CO emissions with HET injection compared to conventional diesel combustion, reaching the value of $2209 \mathrm{ppm}$. It seems possible that these results are due to the ethanol cooling effect, which results in a lower incylinder temperature, making it challenging to complete oxidize of $\mathrm{CO}$ to $\mathrm{CO}_{2}$, resulting in higher $\mathrm{CO}$ emissions.

(f) The experimental data indicates that $\mathrm{NO}_{\mathrm{X}}$ emissions decrease until $21 \%$ of the substitution rate, achieving a value of $290 \mathrm{ppm}$, meaning a decrease of about $20.6 \%$ compared to mono fuel operation. Simultaneously, for substitution rates higher than $21 \%$, the emissions of $\mathrm{NO}_{\mathrm{X}}$ were practically constant. These results are likely to be related to the ethanol cooling effect, which decreases the temperature inside the cylinder, and less $\mathrm{NO}_{\mathrm{X}}$ is formed.

Overall, this study's findings strengthen the idea that utilizing HET in a CI engine running on dual fuel mode is feasible and has a great potential to substitute fossil fuel for a low-carbon fuel, such as hydrous ethanol. As a result, it reduces our dependence on fossil fuels and pollutant emissions. The study contributes to our understanding of using the fumigation method on $\mathrm{CI}$ engines running on ethanol at different loads. The experimental results using high loads, especially $7.0 \mathrm{~kW}$, were the most attractive, resulting in better global efficiency, minimal specific fuel consumption, and a considerable decrease in smoke opacity.

\section{ACKNOWLEDGMENT}

The authors thank CNPQ (Conselho Nacional de Desenvolvimento Científico e Tecnológico) and CAPES (Coordenação de Aperfeiçoamento de Pessoal de Nível Superior) for the financial support.

\section{REFERENCES}

[1] International Energy Agency. (2016). $\mathrm{CO}_{2}$ emissions from fuel combustion.

[2] Mishra, V.K., Goswami, R. (2018). A review of production, properties and advantages of biodiesel. Biofuels, $\quad 9(2)$ : 273-289. https://doi.org/10.1080/17597269.2017.1336350

[3] Bendu, H., Murugan, S. (2014). Homogeneous charge compression ignition (HCCI) combustion: Mixture preparation and control strategies in diesel engines. Renewable and Sustainable Energy Reviews, 38: 732746. https://doi.org/10.1016/j.rser.2014.07.019

[4] Mahadeven, G., Sendilvelan, S. (2017). Temperature analysis of dynamic catalytic convertor system with precatalyst in a multi cylinder spark ignition engine to reduce light-off time. International Journal of Heat and Technology, 35(1): 97-102. https://doi.org/10.18280/ijht.350113

[5] Barik, D., Murugan, S. (2016). Experimental investigation on the behavior of a DI diesel engine fueled with raw biogas e diesel dual fuel at different injection timing. Journal of the Energy Institute, 89(3): 373-388 https://doi.org/10.1016/j.joei.2015.03.002

[6] Hebbar, G.S., Bhat, A.K. (2013). Control of NOx from a DI diesel engine with hot EGR and ethanol fumigation: An experimental investigation. International Journal of Automotive Technology, 14: 333-341. https://doi.org/10.1007/s12239-013-0037-8

[7] Kumar, S., Cho, J.H., Park, J., Moon, I. (2013). Advances in diesel-alcohol blends and their effects on the performance and emissions of diesel engines. Renewable and Sustainable Energy Reviews, 22: 46-72. https://doi.org/10.1016/j.rser.2013.01.017

[8] Trancossi, M., Páscoa, J.C., Xisto, C.M. (2016). Design of an innovative off road hybrid vehicle by energy efficiency criteria. International Journal of Heat and Technology, 34(S2): https://doi.org/10.18280/ijht.34S228

[9] Singh, P., Varun, Chauhan, S.R., Kumar, N. (2016). A review on methodology for complete elimination of diesel from CI engines using mixed feedstock. Renewable and Sustainable Energy Reviews, 57: 11101125. https://doi.org/10.1016/j.rser.2015.12.090

[10] Ayhan, V., Çangal, Ç., Cesur, İ., Safa, A. (2020). Combined influence of supercharging, EGR, biodiesel and ethanol on emissions of a diesel engine: Proposal of an optimization strategy. Energy, 207: 118298. https://doi.org/10.1016/j.energy.2020.118298

[11] Renewable Fuels Association. (2020). Ethanol Industry Outlook.

[12] Prakash, T., Geo, V.E., Martin, L.J., Nagalingam, B. (2018). Effect of ternary blends of bio-ethanol, diesel and castor oil on performance, emission and combustion in a CI engine. Renewable Energy, 122: 301-309. https://doi.org/10.1016/j.renene.2018.01.070

[13] Al-Esawi, N., Al Qubeissi, M., Kolodnytska, R. (2019). The impact of biodiesel fuel on ethanol/diesel blends. Energies, 12(9): 1804. https://doi.org/10.3390/en12091804

[14] Gao, Z., Lin, S., Ji, J., Li, M. (2019). An experimental study on combustion performance and flame spread characteristics over liquid diesel and ethanol-diesel blended fuel. Energy, 170: 349-355. https://doi.org/10.1016/j.energy.2018.12.130

[15] Rosa, J.S., Lorenzini, G., Altafini, C.R., Wander, P.R., Telli, G.D., Rocha, L.A.O. (2019). Performance effects and economic viability of high-hydrated ethanol fumigation and diesel direct injection in a small compression ignition engine. Mathematical Modelling of Engineering Problems, 6(1): 1-9. https://doi.org/10.18280/mmep.060101

[16] Morsy, M.H. (2015). Assessment of a direct injection diesel engine fumigated with ethanol/water mixtures. Energy Conversion and Management, 94: 406-414. https://doi.org/10.1016/j.enconman.2015.01.086

[17] Telli, G.D., Altafini, C.R., Rosa, J.S., Costa, C.A. (2018). Experimental investigation of a compression ignition engine operating on B7 direct injected and hydrous ethanol fumigation. Energy, 165: 106-117. https://doi.org/10.1016/j.energy.2018.09.171

[18] Jamuwa, D.K., Sharma, D., Soni, S.L. (2017). Experimental investigation of performance, exhaust emission and combustion parameters of compression ignition engine with varying ethanol energy fractions. 
Energy,

127:

$544-557$

https://doi.org/10.1016/j.energy.2017.03.121

[19] Beatrice, C., Denbratt, I., Di Blasio, G., Di Luca, G., Ianniello, R., Saccullo, M. (2020). Experimental assessment on exploiting low carbon ethanol fuel in a light-duty dual-fuel compression ignition engine. Applied $\quad$ Sciences, $\quad 10(20)$ : 7182. https://doi.org/10.3390/app10207182

[20] Abedin, M.J., Imran, A., Masjuki, H.H., Kalam, M.A., Shahir, S.A., Varman, M., Ruhul, A.M. (2016). An overview on comparative engine performance and emission characteristics of different techniques involved in diesel engine as dual-fuel engine operation. Renewable and Sustainable Energy Reviews, 60: 306316. https://doi.org/10.1016/j.rser.2016.01.118

[21] Boretti, A. (2012). Advantages of converting diesel engines to run as dual fuel ethanol - diesel. Applied Thermal Engineering, 47: 1-9. https://doi.org/10.1016/j.applthermaleng.2012.04.037

[22] Imran, A., Varman, M., Masjuki, H.H., Kalam, M.A. (2013). Review on alcohol fumigation on diesel engine: A viable alternative dual fuel technology for satisfactory engine performance and reduction of environment concerning emission. Renewable and Sustainable Energy Reviews, 26: 739-751. https://doi.org/10.1016/j.rser.2013.05.070

[23] Chauhan, B.S., Kumar, N., Pal, S.S., Yong, D.J. (2011). Experimental studies on fumigation of ethanol in a small capacity diesel engine. Energy, 36(2): 1030-1038. https://doi.org/10.1016/j.energy.2010.12.005

[24] Han, J., Somers, L.M.T., Cracknell, R., Joedicke, A., Wardle, R., Mohan, V.R.R. (2020). Experimental investigation of ethanol/diesel dual-fuel combustion in a heavy-duty diesel engine. Fuel, 275: 117867. https://doi.org/10.1016/j.fuel.2020.117867

[25] Ferreira, V.P., Martins, J., Torres, E.A., Pepe, I.M., De Souza, J.R. (2013). Performance and emissions analysis of additional ethanol injection on a diesel engine powered with A blend of diesel-biodiesel. Energy for Sustainable Development, 17(6): 649-657. https://doi.org/10.1016/j.esd.2013.08.005

[26] Rosa, J.S., Altafini, C.R., Wander, P.R., Telli, G.D., Rocha, L.A.O. (2019). Wet ethanol fumigation on a compression ignition engine: Effects of air intake throttled. Journal of the Brazilian Society of Mechanical Sciences and Engineering, 41: 500. https://doi.org/10.1007/s40430-019-2023-1

[27] Tsang, K.S., Zhang, Z.H., Cheung, C.S., Chan, T.L. (2010). Reducing emissions of a diesel engine using fumigation ethanol and a diesel oxidation catalyst. Energy \& Fuels, 24(11): 6156-6165. https://doi.org/10.1021/ef100899z

[28] López, A.F., Cadrazco, M., Agudelo, A.F., Corredor, L.A., Vélez, J.A., Agudelo, J.R. (2015). Impact of nbutanol and hydrous ethanol fumigation on the performance and pollutant emissions of an automotive diesel engine. Fuel, 153: 483-491. https://doi.org/10.1016/j.fuel.2015.03.022

[29] Zhang, Z.H., Tsang, K.S., Cheung, C.S., Chan, T.L., Yao,

C.D. (2011). Effect of fumigation methanol and ethanol on the gaseous and particulate emissions of a directinjection diesel engine. Atmospheric Environment, 45(11): 2001-2008 https://doi.org/10.1016/j.atmosenv.2010.12.019

[30] De Oliveira, A., de Morais, A.M., Valente. O.S., Sodré, J.R. (2017). Combustion, performance and emissions of a diesel power generator with direct injection of B7 and port injection of ethanol. Journal of the Brazilian Society of Mechanical Sciences and Engineering, 39: 1087-1096. https://doi.org/10.1007/s40430-016-0667-7

[31] Jamuwa, D.K., Sharma, D., Soni, S.L. (2016). Experimental investigation of performance, exhaust emission and combustion parameters of stationary compression ignition engine using ethanol fumigation in dual fuel mode. Energy Conversion and Management, 115: 221-231. https://doi.org/10.1016/j.enconman.2016.02.055

[32] Jamuwa, D.K., Sharma, D., Soni, S.L. (2019). Performance, emission and combustion analysis of an ethanol fuelled stationary CI engine. Biofuels, 10(5): 569-582. https://doi.org/10.1080/17597269.2016.1163213

[33] Kline, S.J., McClintock, F.A. (1953). Describing Uncertainties in Single-Sample Experiments. Mechanical Engineering, 75: 3-8

[34] Rosa, J.S., Martins, M.E.S., Telli, G.D., Altafini, C.R., Wander, P.R., Rocha, L.A.O. (2020). Exploring the effects of diesel start of injection and water-in-ethanol concentration on a reactivity controlled compression ignition engine. Fuel, 281: 118751. https://doi.org/10.1016/j.fuel.2020.118751

\section{NOMENCLATURE}

B7

$\begin{array}{ll}\text { bTDC } & \text { before the top dead center } \\ \text { CI } & \text { compression ignition } \\ \text { EGT } & \text { exhaust gas temperature } \\ \text { GTE } & \text { global thermal efficiency } \\ \text { HET } & \text { hydrous ethanol } \\ \text { HHV } & \text { higher heating value, } \mathrm{J}^{-1} \\ \text { ICE } & \text { lowernal combustion engine } \\ \text { LHV } & \text { mass flow rate, g. } \mathrm{s}^{-1} \\ \dot{m} & \text { power, } \mathrm{kW} \\ \text { P } & \text { port fuel injection } \\ \text { PFI } & \text { specific fuel consumption, } \mathrm{g} \cdot \mathrm{kW}^{-1} \cdot \mathrm{h}^{-1} \\ \text { SFC } & \end{array}$

\section{Greek symbols}

$\eta$

\section{Subscripts}

$T$

total 